\title{
B Cells as an Immune-Regulatory Signature in Ovarian Cancer
}

\author{
Prachi Gupta, Changliang Chen, Pradeep Chaluvally-Raghavan and Sunila Pradeep* \\ Department of Obstetrics and Gynecology, Medical College of Wisconsin, Milwaukee, WI 53226, USA \\ * Correspondence: spradeep@mcw.edu; Tel.: +1-414-955-2673
}

Received: 3 June 2019; Accepted: 22 June 2019; Published: 26 June 2019

\begin{abstract}
Increasing evidence suggests that the immune system plays a dynamic role in the progression of ovarian cancer, the deadliest gynecological malignancy worldwide. Accumulation of tumor-infiltrating lymphocytes has been associated with increased survival in ovarian cancer patients, and diverse interactions among immune cells in the tumor microenvironment determine tumor progression. While the regulatory functions of $\mathrm{T}$ cells among tumor-infiltrating lymphocytes are well defined and also involve therapeutic interventions, the role of B cells in ovarian cancer progression is still limited to their impact on survival. Recent studies have identified both pro- and anti-tumor responses of B cells in solid tumors, as different subsets of B cells play diverse roles in progression. Thus, in-depth characterization of $B$ cell subtypes in each disease stage is crucial for understanding the importance and therapeutic potential of these cells in ovarian cancer. In this review, we summarize current knowledge about $B$ cells in ovarian cancer and discuss emerging therapeutic interventions that could harness B cells to combat this deadly disease.
\end{abstract}

Keywords: ovarian cancer; B cells; tumor microenvironment; immune cells; tumor infiltrating lymphocytes

\section{Introduction}

Human cancers show divergent immunologic properties [1], requiring the immune system to continually adapt to tumor growth and to hone surveillance strategies [2]. To mediate effective tumor control, the immune system must recognize dynamic tumor heterogeneity and adopt new cycles of immune recognition and attack. Thus, understanding these mechanisms is crucial for developing immunotherapies that yield lasting responses.

Ovarian cancer, the most lethal gynecological malignancy in women worldwide, has the following subtypes [3]: endometrioid carcinoma, clear cell carcinoma, mucinous carcinoma, low-grade serous carcinoma and high-grade serous carcinoma (HGSC). Among these, HGSC accounts for $\sim 68 \%$ of ovarian cancer and has the worst prognosis [3]. Regardless of advances in treatment, $70-80 \%$ of patients who initially respond to therapy ultimately relapse and die [4], often because the disease is diagnosed at late stages. However, accumulating evidence shows that the immunogenicity of ovarian cancer can open the door to immunotherapeutic approaches to treatment. For example, the presence of tumor-infiltrating lymphocytes (TILs) and their correlation with increased survival in ovarian cancer has validated the role of immunotherapy in ovarian cancer [5]. The identification of tumor-associated antigens (TAAs) in ovarian cancer also supports an immunotherapeutic treatment strategy [6].

The potential role of $\mathrm{T}$ cells in antitumor responses is well established and extensively studied. However, the contribution of $B$ cells to tumor immune responses is less well understood. Apart from generating an antibody response against antigens, B cells can also interact with other immune cells through antigen presentation, cytokine secretion and expression of co-stimulating molecules [7]. In the 
tumor microenvironment, functionally distinct subsets of B cells are present, and the balance among subtypes may affect tumor development and behavior [7].

In this review, we highlight recent findings related to the contributions of B cells to pro- or anti-tumor responses in ovarian cancer and their potential relevance to ovarian cancer prevention.

\section{B Cell Markers in Ovarian Cancer}

B cell subsets—naïve B cells, memory B cells, plasma cells and regulatory B (Breg) cells—have been recognized in ovarian cancer. These subsets are identified by distinct molecular markers, as listed in Table 1. We did not include Bregs in the list, as they lack well-defined molecular markers in ovarian cancer, though different Breg phenotypes have been identified in mouse models and other cancer types [8].

Table 1. List of B cell markers used to characterize B cell subtypes in ovarian cancer.

\begin{tabular}{cccc}
\hline Marker & Naïve B Cells & Memory B Cells & Plasma Cells \\
\hline CD20 & + & + & - \\
\hline CD19 & + & + & + \\
\hline CD138 & - & - & + \\
\hline CD38 & - /low & + & + \\
\hline CD95 & - & + & + \\
\hline CD27 & - & - & + \\
\hline IGKC & - & + & + \\
\hline IgG & - & - & - \\
\hline IgD & + & + & - \\
\hline IgM & + & + & - \\
\hline CXCR5 & + & + & + \\
\hline CXCR3 & - & + & + \\
\hline
\end{tabular}

Legend: The markers listed here have been used to study the prognostic significance of B cells in ovarian cancer [9-12]. Markers of Breg are not well defined in the literature: only IL-10 (Interleukin-10 (IL-10)) positive cells are being classified as Bregs [7].

\section{Prognostic Role of B Cells in Ovarian Cancer}

The prognostic significance of tumor-infiltrating lymphocytes has been widely recognized in cancer. For example, a systematic review by Maartje et al. [13] documented that, in most tumor types, $B$ cells and plasma cells have a positive or neutral prognostic effect, with only a minority of studies reporting a negative effect.

In a study of HGSC, infiltration of CD19+ $\mathrm{B}$ cells in to the omentum was associated with poor survival [14]. Another study of metastatic ovarian carcinoma patients also showed that a higher percentage of $\mathrm{CD} 19^{+}$cells and natural killer (NK) cells predicted poor survival, supporting a role for B cells in ovarian cancer [15]. Contrary to those reports, CD20 ${ }^{+}$B-cells correlated with positive survival in a group of 199 ovarian cancer patients [16]. In a sample of 40 ovarian cancer patients, Nielsen et al. [9] demonstrated that CD20 ${ }^{+}$B cells co-localized with activated CD8 ${ }^{+}$TILs $^{2}$ expressing antigen presentation markers and correlated with increased patient survival compared with CD8 ${ }^{+}$TILs alone. Santoiemma et al. [17] also showed that the presence of CD8 ${ }^{+}$and CD20 ${ }^{+}$TILs positively correlated with overall survival. Lundgren et al. [18] found that plasma cell infiltration in to epithelial ovarian cancer significantly impacted tumor progression and prognosis, as high CD138 expression correlated with significantly reduced overall survival. The discrepancies among these studies emphasize the need for more comprehensive studies that also focus on the interactions of B 
cells with other immune cells, and also clearly demonstrate the abundance of B cell subtypes in studied ovarian cancer patients.

\section{Role of Regulatory B Cells (Bregs) in Ovarian Cancer}

Bregs are a subset of B cells that produce IL-10 [19] but there are currently no precise surface markers for identifying them. B cells expressing surface molecular markers such as CD1 and CD5 have been shown to secrete IL-10, which is immunosuppressive. However, different Breg phenotypes have been described in different cancer types [19]. The immunoregulatory functions of Breg cells have been investigated in different cancer models, shifting our understanding of how Breg function is regulated during tumor progression has become frontier of cancer immunotherapy. Moreover, analysis of the expression of several immunosuppressive membrane-bound molecules (such as CD80, CD86, PDL1, PD1, Fas-L, CD40L and OX40L) and secretion of various cytokines (such as IL-10, TGF- $\beta$ and IL-35) by Bregs in specific tumor settings and stages of cancer has revealed functional complexity among the subsets of tumor-evoked Bregs [20].

Various subsets of Bregs have been identified in diverse solid tumors such as ovarian, bladder, breast, pancreatic, colorectal, lung, squamous cells and hepatocellular [8], where they promote tumor growth and suppress cellular immune responses through diverse mechanisms. As demonstrated by a study in a $4 \mathrm{~T} 1$ breast cancer murine model, a unique subset of Bregs $\left(\mathrm{CD} 25^{+} \mathrm{CD} 19^{+} \mathrm{B} 22 \mathrm{0}^{+}\right.$cells) constitutively expresses STAT3 and promotes tumor metastasis through TGF $\beta$-dependent conversion of effector T cells to regulatory T cells (Tregs) [21].

Tumor-infiltrating B cells (TIL-B) acquire immunosuppressive properties as they come in to contact with tumor cells. Such tumor-evoked Bregs (tBregs) have been found in various human tumors [8]. Using an EMT-6 breast cancer model, Zhang et al. [22] found that TIL-B cells developed increased expression of PD-L1, CD86, CD80 and LAP/TGF- $\beta$ in comparison to splenic B cells. These TIL-B cells also suppressed the proliferation of $\mathrm{CD}^{+}$and $\mathrm{CD} 8^{+} \mathrm{T}$ cells in vitro. Moreover, several factors that induce tBregs are found in the tumor microenvironment, including TNF- $\alpha$ (secreted by tumor cells) and IL-21 (secreted by T cells) [23,24]. Other than soluble factors, some of the cell-cell contact ligands, such as CD40L and PD-L1, that are expressed on tumor cells induce tBregs in the tumor microenvironment [7]. In addition to extensive studies on how the PD-1-PD-L1 axis allows tumors to escape from the immune system, a recent study showed that the eIF4F-STAT1-PD-L1 axis promotes PD-L1 expression on tumor cells and inhibitors of eIF4A (the RNA helicase component of eIF4F) could be developed as anticancer drugs, because inhibition of eIF4A downregulates PD-L1 expression on tumor cells [25].

Different signaling mechanisms have been identified in tumor-promoting Bregs. For example, one subtype of Bregs $\left(\mathrm{CD} 19^{ \pm} \mathrm{CD} 1 \mathrm{~d}^{\text {high }} \mathrm{CD} 5^{ \pm}\right.$) promoted tumor growth in a mouse model of pancreatic ductal adenocarcinoma (PDAC) mediated by IL-35 signaling [26], making IL-35 a suitable therapeutic intervention in some human tumors. Bruton's tyrosine kinase (BKT) signaling was also shown to suppress anti-tumor immunity by infiltrating lymphocytes in PDAC tumors. Activated BTK was identified in murine PDAC tumors, and was most prominent in $\mathrm{CD} 19^{+} \mathrm{B}$ cells and myeloid cells [27]. A BKT inhibitor, ibrutinib, is in clinical trials in various human tumors [8]

Breg cells that express GrB have also been seen in ovarian cancer tissue [18]. Moreover, Bregs induced the conversion of FoxP3 ${ }^{+}$Tregs from resting $\mathrm{CD}^{+} \mathrm{T}$ cells, supporting cancer metastasis [21]. A study in ovarian cancer patients showed an enriched population of IL- $10^{+} \mathrm{B}$ cells in ascites, and their frequencies positively correlated with Foxp $3^{+} \mathrm{CD}^{+} \mathrm{T}$ cells. Those B cells also suppressed IFN-g production by $\mathrm{CD} 8^{+} \mathrm{T}$ cells, showing that Breg cells can inhibit the antitumor adaptive immune responses in the tumor microenvironment [10]. Cancer cells could convert normal B cells to Bregs, thus inhibiting the antitumor immune response [19]. These findings have important clinical implications, as they suggest that Bregs must be controlled to interrupt the initiation of a key cancer-induced immunosuppressive event. 


\section{Humoral Immunity in Ovarian Cancer}

Autoantibody responses associated with B cells have been found in many tumor types. Tumor-associated autoantibodies (AAbs) are produced as an immune response to aberrantly expressed, mutated, or post-translationally modified proteins or other autoantigens associated with tumors, and they may be enhanced by tumor-associated inflammation [28]. This class of biomarkers is highly valued, as AAbs exhibit several properties that make them attractive as early detection biomarkers. First, circulating antibodies are more stable over time than their corresponding antigens, which are subject to proteolysis, whereas antibodies are not [29]. Second, the immune response to tumor-associated antigens amplifies the signal. Therefore, AAbs may be detectable sooner than antigens themselves [29], potentially allowing detection at an earlier disease stage. Finally, AAb ELISA assays are readily translatable to clinical chemistry platforms. Therefore, AAb panels providing validated diagnostic discrimination could readily be added to the best available screening markers for clinical implementation.

Several AAbs have been identified in sera of ovarian cancer patients, and their levels correlate with specific tumor types and stages. A recent review by Fortner et al. identified 85 AAbs that discriminated between ovarian cancer cases and controls [30]. This study also analyzed a panel of AAb biomarkers to check their diagnostic performance in ovarian cancer. This panel, which included 11 AAbs (ICAM3, CTAG2, p53, STYXL1, PVR, POMC, NUDT11, TRIM39, UHMK1, KSR1 and NXF3), provided 45\% sensitivity and $98 \%$ specificity for serous ovarian cancer. Single AAbs have much less sensitivity and specificity and therefore less potential as biomarkers. However, the clinical performance of any AAb biomarker depends highly on clinical stage, histology, age, treatment schedule and subjects' general health. Thus, any biomarker study must keep all these factors in mind and associate clinically proven markers, such as CA125 and HE4 (in the case of ovarian cancer), with identified novel biomarkers. For example, a study by Wilson et al. [31] in early-stage HGSC, found that AAbs against HSF1 detected early stage malignancy better than CA125 alone and that combined measurements of anti-HSF1, anti-CCDC155 and CA125 might be useful for detecting early stage HGSC, thus highlighting the potential role of AAb biomarkers in detection of early disease. Another study, by Chatterjee et al. [32], suggested a role for AAbs in the surveillance of ovarian cancer and in predicting its recurrence, as AAbs to 5H6, HARS, CDR2 and Ro52 antigens predicted ovarian cancer recurrence 5.03 months before clinical onset in 21 patients, with a sensitivity of $90.5 \%$. In contrast, levels of the known biomarker CA125 were below the standard cutoff $(35 \mathrm{U} / \mathrm{mL})$.

Most of the study considering the diagnostic potential of AAbs still have not discovered their role in prognosis of ovarian cancer. Although P53 AAbs have been associated with overall good survival in this cancer, there are still contradictory findings in case of the predictive value of p53 AAbs in ovarian cancer [33]. However, the prognostic utility of AAbs has been observed in other cancer types [34]. Also, an interesting finding about the therapeutic use of AAbs has been emerged. A circulating AAb against GRP78 protein was found to reduce invasiveness and increase apoptosis in ovarian cancer [35]. A follow-up study in chick embryo cultures of ovarian cancer cells treated the tumors with paclitaxel-loaded nanoparticles coated with anti-GRP78 antibodies [36]. That strategy decreased tumor growth compared with paclitaxel treatment alone, suggesting that delivering cancer drugs along with antibodies could be a powerful therapy against ovarian cancer. However, a recent study uncovered a pathogenic role for B cell-secreted antibodies in breast carcinoma: tumor-educated $\mathrm{B}$ cells and their derived antibodies formed a pre-metastatic niche, where they promoted lymph node metastasis by producing IgG that targeted HSPA4 [37]. Such studies warrant further investigations, as they showcase the importance of pathogenic antibodies in different tumor types.

\section{Cross-Talk between B cells and the Tumor Microenvironment}

The role of B cells extends beyond eliciting humoral immune responses. B cells can recognize antigens, regulate antigen processing and presentation, and modulate $\mathrm{T}$ cells and innate immune responses. Moreover, B cells can potentially influence all immune cells that express Fc receptors, such 
as dendritic cells (DC), granulocytes, natural killer cells (NK), and myeloid-derived suppressor cells (MDSCs). Also, studies of other cancers have suggested both pro-and anti-immune responses of B cells [7]. Due to the small number of investigations, however, the exact scenario of $B$ cells in ovarian cancer is unknown.

A recent breast cancer study showed that $B$ cells suppressed the antitumor immune response in tumor-bearing mice by expressing LAP/TGF- $\beta$ and PD-L1, markedly reducing CD8 ${ }^{+} \mathrm{T}$ cell and $\mathrm{CD} 49^{+} \mathrm{NK}$ cell infiltration, and reducing cytolytic T cell response [22]. Another study that focused on the interaction between tumor cells and tumor-associated B cells in melanoma found that B cells induced a heterogenous population of cancer cells that phenotypically resembled cancer stem cells. Those B cells also induced therapy resistance by secreting IGF1 [38]. In contrast, Montfort et al. [11] found that B cell infiltration in to HGSC supported the development of an antitumor response. The strong memory B cell response was even enhanced by chemotherapy. The group also showed that omental B cells produced a network of cytokines and chemokines, including IFNg, IL12, GM-CSF and CXCL10, supporting an antitumor response. In line with these findings, another study showed that the presence of both $\mathrm{CD} 8^{+}$TIL CD20 ${ }^{+}$B cells in HGSC was highly prognostic, suggesting that cooperative interactions between these lymphocyte subsets strengthens antitumor immunity [12]. Thus, key factors that facilitate a coordinated $\mathrm{CD} 8^{+} \mathrm{T}$ cell and $\mathrm{CD} 2 \mathrm{O}^{+} \mathrm{B}$ cell response should be defined, and immunotherapies should be designed to enhance not only $\mathrm{CD} 8^{+} \mathrm{T}$ cells but also $\mathrm{CD} 20^{+} \mathrm{B}$ cells in the fight against cancer [39]. However, B cells have been seen to foster squamous cell carcinoma (SCC) by activating $\mathrm{Fc}_{\mathrm{c}} \gamma$ receptors ( $\mathrm{F} \gamma \mathrm{Rs}$ ) on resident and recruited myeloid cells and further repolarizing tumor-associated macrophages toward an immunosuppressive phenotype (M2-type) [40,41]. When PDAC-derived B cells were co-cultured with macrophages, PDAC-derived B cells also repolarized macrophages into the immunosuppressive and tumorigenic M2-type [27]. Such MDSCs acquire immunosuppressive and tumor-promoting functions, thus encouraging tumor growth and metastasis in tumor microenvironment $[42,43]$.

B cells can achieve antitumor immunity by secreting IFN $\gamma$, facilitating $\mathrm{CD} 4^{+}$Th cells to polarize to Th1 responses, and promoting T cell expansion by presenting TAAs [7]. Conversely, Bregs were recently designated as immunosuppressive cells that can secrete anti-inflammatory mediators, such as IL-10, IL-35 and TGF- $\beta$, to convert T cells in to Tregs [44]. Recently, an excellent study by Ouyang et al. [45] showed that a subset of semi-mature dendritic cells (DCs) in the tumor microenvironment activated B cell differentiation toward the Fc $\gamma$ RII low/IL-10 Breg phenotype. Another recent study, using IHC, found tumor-infiltrating CD20 $0^{+}$cells in $>50 \%$ of patients with HGSC exhibited a robust positive correlation with DC-LAMP ${ }^{+}$DC density, in both the tumor stroma and tumor nests and also associated with the highest overall survival in HGSC [46]. Thus, this study highlights the roles of DC and B cell-mediated antitumor immunity in the HGSC tumor microenvironment.

\section{B Cells Associate with Tertiary Lymphoid Structures (TLS) in Tumors}

Tumor-associated TLS— that form at sites of inflammation—have been noted in cancer recently [47]. There is compelling evidences that immune responses can develop in TLS that are associated with tumor tissue independently of responses from secondary lymphoid organs [47]. The presence of TLS in tumor tissue has largely associated with a favorable prognosis for patients with solid tumor types such as lung, colorectal, breast and prostate, as well as in ovarian carcinoma [47].

Different types of immune cells, such as B cells, T cells and DCs, have been seen with in TLS. Also, the presence of $\mathrm{B}$ cells associated with TLS has correlated with better prognosis in non-small cell lung carcinoma (NSCLC) and colorectal, ovarian and pancreatic cancers [48-51]. More recently, in HGSC omentum tissue, the presence of B cells in TLS associated with the generation of a memory B cell response and with infiltration of DCs in to omentum tissue. Furthermore, TLS were shown to contain large aggregates of plasma cells that had a high level of IgG deposition [11]. Thus, Montfort et al. showed that B cells in TLS played a positive role in the antitumor response, though their presence did not correlate with patients' survival. A study by Kroeger et al. [12] supported these findings in 
HGSC, as it reported high aggregates of antibody-producing plasma cells in TLS. The plasma cells correlated with a prognostically favorable $\mathrm{CD} 8^{+} \mathrm{T}$ cells response. Overall, the presence of $\mathrm{B}$ cells in TLS is a marker of increased patient survival in ovarian cancer and other solid tumor types.

\section{Prospects and Conclusions}

This review has focused on the field of B cell regulation in ovarian cancer. After a rigorous literature search, we realized that studies of $B$ cells in ovarian cancer are very limited, though recent work with other cancer models has identified B cells as an attractive immunotherapeutic target. In the case of ovarian cancer, there could be a similar scenario, but there are still many unanswered questions. First, does the presence of B cells in the tumor vicinity support tumor growth or does it indicate anti-tumor activity? That role also needs to be associated with the subtype of $B$ cell in the tumor microenvironment. As the presence of $\mathrm{CD} 20^{+} \mathrm{B}$ cells has been associated with increased survival in ovarian cancer patients, these cells may play an anti-tumor role. In contrast, the presence of Bregs imparts immunosuppressive effects, supporting tumor growth. Anti-CD20 antibodies targeted to B cells, such as Rituximab and obinatuzumab, have been developed, but they have not been very effective in several tumor models [8]. To augment the anti-tumor response, it will necessary to identify the key B cell subset that has a regulatory function.

The second emerging question in B cell biology involves immunosuppressive Bregs. Although Bregs have been detected in ovarian cancer and are known to be immunosuppressive, there are still no well-known surface markers for defining Bregs as prognostic biomarkers in that disease. It would also be interesting to know which cellular or soluble factors are involved in the induction of Bregs in cancer progression. Moreover, it is still unclear whether Bregs are specific subsets of B cells or whether all types of B cells can convert to immunosuppressive Bregs. Therefore, the exact mechanisms underlying the origin and differentiation of Bregs in the tumor microenvironment merit further investigation, as these factors reset the immune system.

The third interesting investigation would be to explore the role of antibody-producing plasma cells in ovarian cancer. Several AAbs have diagnostic potential in that disease, but it is unclear whether they attack tumor cells or play a tumor-supportive role. As shown by a few studies, AAbs can be used for targeted delivery of drugs into tumor cells. For example, another cell penetrating anti-DNA AAbs 3E10 has been isolated from alupus-prone murine model that can deliver proteins and drugs specifically to cancer cells [52]. Future investigations will explore this therapeutic intervention in ovarian cancer. However, the utility of AAbs seems to be limited by the immunosuppressive microenvironment and because of poor anti-tumor potency. Therefore, it would be interesting to find ways to enhance the potency of AAbs.

Finally, a considerable effort is needed to explain how B cells behave in the tumor microenvironment. As anti-B-cell treatments have shown limited efficacy in cancer patients, understanding immunosuppressive interactions among immune cells should lead to more patient-specific therapies. Another emerging goal would be to determine tumor cells' capacity to regulate B cell proliferation and convert them into Bregs. The cytokines and cell-cell contact factors involved in these processes also need to be identified. Furthermore, how Bregs support the proliferation of Tregs and control the activation of other immune cells, such as NK cells, DC cells and myeloid-derived suppressor cells, should remain a field of active investigation (Figure 1).

Thus, this review highlights potential B cell-mediated therapies and showcases emerging areas of research in this field. As B cells play a central role in the tumor microenvironment, we anticipate that $B$ cell-mediated immunotherapies will greatly benefit ovarian cancer patients. 


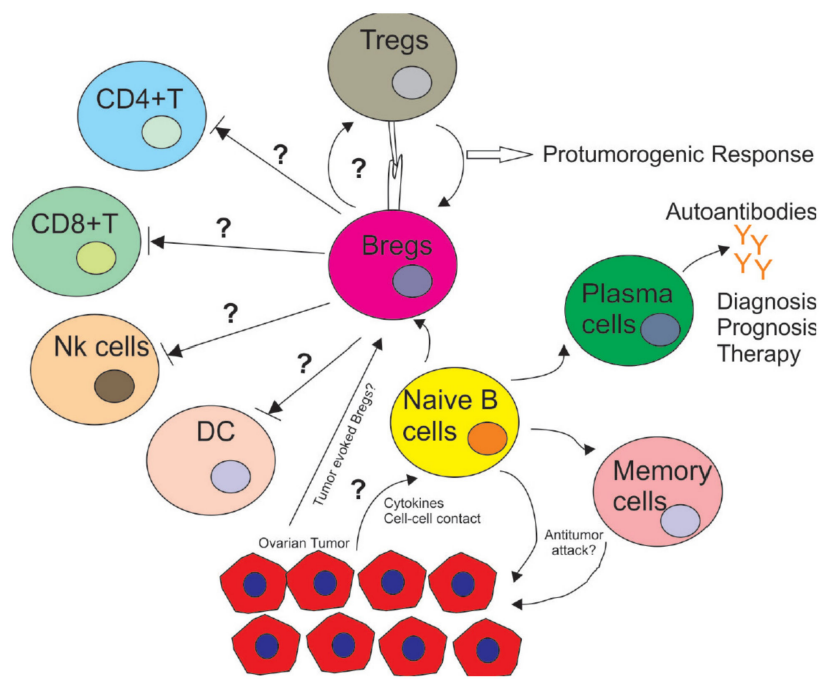

Figure 1. Immuno-regulatory role of B cells in the tumor microenvironment in ovarian cancer. The tumor microenvironment induces naïve B cells to differentiate into subsets, such as Bregs, plasma cells and memory B cells. These subsets play different roles as Bregs inhibit the proliferation of CD4 ${ }^{+} \mathrm{T}$ cells, $\mathrm{CD}^{+} \mathrm{T}$ cells, DCs and NK cells while supporting the proliferation of immune-inhibitory Tregs with unknown cytokines and cell-cell contacts. On the other hand, some subsets of B cells whose markers are unknown also induce an anti-tumor response with $\mathrm{CD}^{+}$TILs, inhibiting tumor progression. Plasma cells secrete autoantibodies that can play a variety of roles in cancer diagnosis, prognosis and therapy. It is unknown if autoantibodies can also support tumor development.

Author Contributions: All authors contributed to the research, writing and editing of this review article.

Funding: S.P. is supported by the Ovarian Cancer Research Fund Alliance (OCRFA) and by research funds from Women's Health Research Program (WHRP) in the Department of Obstetrics and Gynecology at the Medical College of Wisconsin (MCW). P.C.-R. is supported by the OCRFA, DoD Breast Cancer Research Program (W81XWH-18-1-0024 and WHRP at MCW.

Conflicts of Interest: The authors declare no conflict of interest.

\section{References}

1. Tabassum, D.P.; Polyak, K. Tumorigenesis: It takes a village. Nat. Rev. Cancer 2015, 15, 473-483. [CrossRef] [PubMed]

2. Ribatti, D. The concept of immune surveillance against tumors. The first theories. Oncotarget 2017, 8, 7175-7180. [CrossRef] [PubMed]

3. Koshiyama, M.; Matsumura, N.; Konishi, I. Subtypes of Ovarian Cancer and Ovarian Cancer Screening. Diagnostics 2017, 7, 17. [CrossRef] [PubMed]

4. Armstrong, D.K. Relapsed ovarian cancer: Challenges and management strategies for a chronic disease. Oncologist 2002, 7, 20-28. [CrossRef] [PubMed]

5. Pages, F.; Galon, J.; Dieu-Nosjean, M.C.; Tartour, E.; Sautes-Fridman, C.; Fridman, W.H. Immune infiltration in human tumors: A prognostic factor that should not be ignored. Oncogene 2010, 29, 1093-1102. [CrossRef]

6. Rodriguez, G.M.; Galpin, K.J.C.; McCloskey, C.W.; Vanderhyden, B.C. The Tumor Microenvironment of Epithelial Ovarian Cancer and Its Influence on Response to Immunotherapy. Cancers 2018, 10, 242. [CrossRef]

7. Sarvaria, A.; Madrigal, J.A.; Saudemont, A. B cell regulation in cancer and anti-tumor immunity. Cell Mol. Immunol. 2017, 14, 662-674. [CrossRef]

8. Schwartz, M.; Zhang, Y.; Rosenblatt, J.D. B cell regulation of the anti-tumor response and role in carcinogenesis. J. Immunother. Cancer 2016, 4, 40. [CrossRef]

9. Nielsen, J.S.; Sahota, R.A.; Milne, K.; Kost, S.E.; Nesslinger, N.J.; Watson, P.H.; Nelson, B.H. CD20+ tumor-infiltrating lymphocytes have an atypical CD27- memory phenotype and together with CD8+ T cells promote favorable prognosis in ovarian cancer. Clin. Cancer Res. 2012, 18, 3281-3292. [CrossRef] 
10. Wei, X.; Jin, Y.; Tian, Y.; Zhang, H.; Wu, J.; Lu, W.; Lu, X. Regulatory B cells contribute to the impaired antitumor immunity in ovarian cancer patients. Tumour Biol. 2016, 37, 6581-6588. [CrossRef]

11. Montfort, A.; Pearce, O.; Maniati, E.; Vincent, B.G.; Bixby, L.; Bohm, S.; Dowe, T.; Wilkes, E.H.; Chakravarty, P.; Thompson, R.; et al. A Strong B-cell Response Is Part of the Immune Landscape in Human High-Grade Serous Ovarian Metastases. Clin. Cancer Res. 2017, 23, 250-262. [CrossRef] [PubMed]

12. Kroeger, D.R.; Milne, K.; Nelson, B.H. Tumor-Infiltrating Plasma Cells Are Associated with Tertiary Lymphoid Structures, Cytolytic T-Cell Responses, and Superior Prognosis in Ovarian Cancer. Clin. Cancer Res. 2016, 22, 3005-3015. [CrossRef] [PubMed]

13. Wouters, M.C.A.; Nelson, B.H. Prognostic Significance of Tumor-Infiltrating B Cells and Plasma Cells in Human Cancer. Clin. Cancer Res. 2018, 24, 6125-6135. [CrossRef] [PubMed]

14. Yang, C.; Lee, H.; Jove, V.; Deng, J.; Zhang, W.; Liu, X.; Forman, S.; Dellinger, T.H.; Wakabayashi, M.; Yu, H.; et al. Prognostic significance of B-cells and pSTAT3 in patients with ovarian cancer. PLoS ONE 2013,8, e54029. [CrossRef] [PubMed]

15. Dong, H.P.; Elstrand, M.B.; Holth, A.; Silins, I.; Berner, A.; Trope, C.G.; Davidson, B.; Risberg, B. NK- and B-cell infiltration correlates with worse outcome in metastatic ovarian carcinoma. Am. J. Clin. Pathol. 2006, 125, 451-458. [CrossRef] [PubMed]

16. Milne, K.; Kobel, M.; Kalloger, S.E.; Barnes, R.O.; Gao, D.; Gilks, C.B.; Watson, P.H.; Nelson, B.H. Systematic analysis of immune infiltrates in high-grade serous ovarian cancer reveals CD20, FoxP3 and TIA-1 as positive prognostic factors. PLoS ONE 2009, 4, e6412. [CrossRef] [PubMed]

17. Santoiemma, P.P.; Reyes, C.; Wang, L.P.; McLane, M.W.; Feldman, M.D.; Tanyi, J.L.; Powell, D.J., Jr. Systematic evaluation of multiple immune markers reveals prognostic factors in ovarian cancer. Gynecol. Oncol. 2016, 143, 120-127. [CrossRef] [PubMed]

18. Lundgren, S.; Berntsson, J.; Nodin, B.; Micke, P.; Jirstrom, K. Prognostic impact of tumour-associated B cells and plasma cells in epithelial ovarian cancer. J. Ovarian Res. 2016, 9, 21. [CrossRef]

19. He, Y.; Qian, H.; Liu, Y.; Duan, L.; Li, Y.; Shi, G. The roles of regulatory B cells in cancer. J. Immunol. Res. 2014, 2014, 215471. [CrossRef]

20. Mion, F.; Tonon, S.; Valeri, V.; Pucillo, C.E. Message in a bottle from the tumor microenvironment: Tumor-educated DCs instruct B cells to participate in immunosuppression. Cell Mol. Immunol. 2017, 14, 730-732. [CrossRef]

21. Olkhanud, P.B.; Damdinsuren, B.; Bodogai, M.; Gress, R.E.; Sen, R.; Wejksza, K.; Malchinkhuu, E.; Wersto, R.P.; Biragyn, A. Tumor-evoked regulatory B cells promote breast cancer metastasis by converting resting CD4(+) T cells to T-regulatory cells. Cancer Res. 2011, 71, 3505-3515. [CrossRef] [PubMed]

22. Zhang, Y.; Morgan, R.; Chen, C.; Cai, Y.; Clark, E.; Khan, W.N.; Shin, S.U.; Cho, H.M.; Al Bayati, A.; Pimentel, A.; et al. Mammary-tumor-educated B cells acquire LAP/TGF-beta and PD-L1 expression and suppress anti-tumor immune responses. Int. Immunol. 2016, 28, 423-433. [CrossRef]

23. Schioppa, T.; Moore, R.; Thompson, R.G.; Rosser, E.C.; Kulbe, H.; Nedospasov, S.; Mauri, C.; Coussens, L.M.; Balkwill, F.R. B regulatory cells and the tumor-promoting actions of TNF-alpha during squamous carcinogenesis. Proc. Natl. Acad Sci. USA 2011, 108, 10662-10667. [CrossRef] [PubMed]

24. Lindner, S.; Dahlke, K.; Sontheimer, K.; Hagn, M.; Kaltenmeier, C.; Barth, T.F.; Beyer, T.; Reister, F.; Fabricius, D.; Lotfi, R.; et al. Interleukin 21-induced granzyme B-expressing B cells infiltrate tumors and regulate $\mathrm{T}$ cells. Cancer Res. 2013, 73, 2468-2479. [CrossRef] [PubMed]

25. Cerezo, M.; Guemiri, R.; Druillennec, S.; Girault, I.; Malka-Mahieu, H.; Shen, S.; Allard, D.; Martineau, S.; Welsch, C.; Agoussi, S.; et al. Translational control of tumor immune escape via the eIF4F-STAT1-PD-L1 axis in melanoma. Nat. Med. 2018, 24, 1877-1886. [CrossRef] [PubMed]

26. Pylayeva-Gupta, Y.; Das, S.; Handler, J.S.; Hajdu, C.H.; Coffre, M.; Koralov, S.B.; Bar-Sagi, D. IL35-Producing B Cells Promote the Development of Pancreatic Neoplasia. Cancer Discov. 2016, 6, 247-255. [CrossRef]

27. Gunderson, A.J.; Kaneda, M.M.; Tsujikawa, T.; Nguyen, A.V.; Affara, N.I.; Ruffell, B.; Gorjestani, S.; Liudahl, S.M.; Truitt, M.; Olson, P.; et al. Bruton Tyrosine Kinase-Dependent Immune Cell Cross-talk Drives Pancreas Cancer. Cancer Discov. 2016, 6, 270-285. [CrossRef]

28. Zaenker, P.; Gray, E.S.; Ziman, M.R. Autoantibody Production in Cancer-The Humoral Immune Response toward Autologous Antigens in Cancer Patients. Autoimmun. Rev. 2016, 15, 477-483. [CrossRef]

29. Lu, H.; Goodell, V.; Disis, M.L. Humoral immunity directed against tumor-associated antigens as potential biomarkers for the early diagnosis of cancer. J. Proteome Res. 2008, 7, 1388-1394. [CrossRef] 
30. Fortner, R.T.; Damms-Machado, A.; Kaaks, R. Systematic review: Tumor-associated antigen autoantibodies and ovarian cancer early detection. Gynecol. Oncol. 2017, 147, 465-480. [CrossRef]

31. Wilson, A.L.; Moffitt, L.R.; Duffield, N.; Rainczuk, A.; Jobling, T.W.; Plebanski, M.; Stephens, A.N. Autoantibodies against HSF1 and CCDC155 as Biomarkers of Early-Stage, High-Grade Serous Ovarian Cancer. Cancer Epidemiol. Biomarkers Prev. 2018, 27, 183-192. [CrossRef] [PubMed]

32. Chatterjee, M.; Hurley, L.C.; Levin, N.K.; Stack, M.; Tainsky, M.A. Utility of paraneoplastic antigens as biomarkers for surveillance and prediction of recurrence in ovarian cancer. Cancer Biomark 2017, 20, 369-387. [CrossRef] [PubMed]

33. Garziera, M.; Montico, M.; Bidoli, E.; Scalone, S.; Sorio, R.; Giorda, G.; Lucia, E.; Toffoli, G. Prognostic Role of Serum Antibody Immunity to p53 Oncogenic Protein in Ovarian Cancer: A Systematic Review and a Meta-Analysis. PLoS ONE 2015, 10, e0140351. [CrossRef] [PubMed]

34. Wu, J.; Li, X.; Song, W.; Fang, Y.; Yu, L.; Liu, S.; Churilov, L.P.; Zhang, F. The roles and applications of autoantibodies in progression, diagnosis, treatment and prognosis of human malignant tumours. Autoimmun. Rev. 2017, 16, 1270-1281. [CrossRef] [PubMed]

35. Cohen, M.; Petignat, P. Purified autoantibodies against glucose-regulated protein 78 (GRP78) promote apoptosis and decrease invasiveness of ovarian cancer cells. Cancer Lett. 2011, 309, 104-109. [CrossRef] [PubMed]

36. Van Hoesen, K.; Meynier, S.; Ribaux, P.; Petignat, P.; Delie, F.; Cohen, M. Circulating GRP78 antibodies from ovarian cancer patients: A promising tool for cancer cell targeting drug delivery system? Oncotarget 2017, 8, 107176-107187. [CrossRef] [PubMed]

37. Gu, Y.; Liu, Y.; Fu, L.; Zhai, L.; Zhu, J.; Han, Y.; Jiang, Y.; Zhang, Y.; Zhang, P.; Jiang, Z.; et al. Tumor-educated B cells selectively promote breast cancer lymph node metastasis by HSPA4-targeting IgG. Nat. Med. 2019, 25, 312-322. [CrossRef] [PubMed]

38. Somasundaram, R.; Zhang, G.; Fukunaga-Kalabis, M.; Perego, M.; Krepler, C.; Xu, X.; Wagner, C.; Hristova, D.; Zhang, J.; Tian, T.; et al. Tumor-associated B-cells induce tumor heterogeneity and therapy resistance. Nat. Commun. 2017, 8, 607. [CrossRef]

39. Nielsen, J.S.; Nelson, B.H. Tumor-infiltrating B cells and T cells: Working together to promote patient survival. Oncoimmunology 2012, 1, 1623-1625. [CrossRef]

40. Affara, N.I.; Ruffell, B.; Medler, T.R.; Gunderson, A.J.; Johansson, M.; Bornstein, S.; Bergsland, E.; Steinhoff, M.; Li, Y.; Gong, Q.; et al. B cells regulate macrophage phenotype and response to chemotherapy in squamous carcinomas. Cancer Cell 2014, 25, 809-821. [CrossRef]

41. Andreu, P.; Johansson, M.; Affara, N.I.; Pucci, F.; Tan, T.; Junankar, S.; Korets, L.; Lam, J.; Tawfik, D.; DeNardo, D.G.; et al. FcRgamma activation regulates inflammation-associated squamous carcinogenesis. Cancer Cell 2010, 17, 121-134. [CrossRef] [PubMed]

42. Bodogai, M.; Moritoh, K.; Lee-Chang, C.; Hollander, C.M.; Sherman-Baust, C.A.; Wersto, R.P.; Araki, Y.; Miyoshi, I.; Yang, L.; Trinchieri, G.; et al. Immunosuppressive and Prometastatic Functions of Myeloid-Derived Suppressive Cells Rely upon Education from Tumor-Associated B Cells. Cancer Res. 2015, 75, 3456-3465. [CrossRef] [PubMed]

43. Ozkan, B.; Lim, H.; Park, S.G. Immunomodulatory Function of Myeloid-Derived Suppressor Cells during B Cell-Mediated Immune Responses. Int. J. Mol. Sci. 2018, 19, 1468. [CrossRef] [PubMed]

44. Rosser, E.C.; Mauri, C. Regulatory B cells: Origin, phenotype, and function. Immunity 2015, 42, 607-612. [CrossRef] [PubMed]

45. Ouyang, F.Z.; Wu, R.Q.; Wei, Y.; Liu, R.X.; Yang, D.; Xiao, X.; Zheng, L.; Li, B.; Lao, X.M.; Kuang, D.M. Dendritic cell-elicited B-cell activation fosters immune privilege via IL-10 signals in hepatocellular carcinoma. Nat. Commun. 2016, 7, 13453. [CrossRef] [PubMed]

46. Truxova, I.; Kasikova, L.; Hensler, M.; Skapa, P.; Laco, J.; Pecen, L.; Belicova, L.; Praznovec, I.; Halaska, M.J.; Brtnicky, T.; et al. Mature dendritic cells correlate with favorable immune infiltrate and improved prognosis in ovarian carcinoma patients. J. Immunother. Cancer 2018, 6, 139. [CrossRef] [PubMed]

47. Colbeck, E.J.; Ager, A.; Gallimore, A.; Jones, G.W. Tertiary Lymphoid Structures in Cancer: Drivers of Antitumor Immunity, Immunosuppression, or Bystander Sentinels in Disease? Front. Immunol. 2017, 8, 1830. [CrossRef] [PubMed] 
48. Dieu-Nosjean, M.C.; Antoine, M.; Danel, C.; Heudes, D.; Wislez, M.; Poulot, V.; Rabbe, N.; Laurans, L.; Tartour, E.; de Chaisemartin, L.; et al. Long-term survival for patients with non-small-cell lung cancer with intratumoral lymphoid structures. J. Clin. Oncol. 2008, 26, 4410-4417. [CrossRef]

49. Bindea, G.; Mlecnik, B.; Tosolini, M.; Kirilovsky, A.; Waldner, M.; Obenauf, A.C.; Angell, H.; Fredriksen, T.; Lafontaine, L.; Berger, A.; et al. Spatiotemporal dynamics of intratumoral immune cells reveal the immune landscape in human cancer. Immunity 2013, 39, 782-795. [CrossRef]

50. Germain, C.; Gnjatic, S.; Tamzalit, F.; Knockaert, S.; Remark, R.; Goc, J.; Lepelley, A.; Becht, E.; Katsahian, S.; Bizouard, G.; et al. Presence of B cells in tertiary lymphoid structures is associated with a protective immunity in patients with lung cancer. Am. J. Respir. Crit. Care Med. 2014, 189, 832-844. [CrossRef]

51. Hiraoka, N.; Ino, Y.; Yamazaki-Itoh, R.; Kanai, Y.; Kosuge, T.; Shimada, K. Intratumoral tertiary lymphoid organ is a favourable prognosticator in patients with pancreatic cancer. Br. J. Cancer 2015, 112, 1782-1790. [CrossRef] [PubMed]

52. Rattray, Z.; Dubljevic, V.; Rattray, N.J.W.; Greenwood, D.L.; Johnson, C.H.; Campbell, J.A.; Hansen, J.E. Re-engineering and evaluation of anti-DNA autoantibody 3E10 for therapeutic applications. Biochem. Biophys. Res. Commun. 2018, 496, 858-864. [CrossRef] [PubMed]

(C) 2019 by the authors. Licensee MDPI, Basel, Switzerland. This article is an open access article distributed under the terms and conditions of the Creative Commons Attribution (CC BY) license (http://creativecommons.org/licenses/by/4.0/). 